\title{
On-line combination of liquid chromatography and capillary gas chromatography : preconcentration and analysis of organic compounds in aqueous samples
}

\author{
Citation for published version (APA): \\ Noij, T. H. M., Weiss, E., Herps, T., Cruchten, van, H., \& Rijks, J. A. (1988). On-line combination of liquid \\ chromatography and capillary gas chromatography : preconcentration and analysis of organic compounds in \\ aqueous samples. HRC \& CC, Journal of High Resolution Chromatography and Chromatography \\ Communications, 11(2), 181-186. https://doi.org/10.1002/jhrc.1240110208
}

DOI:

10.1002/jhrc. 1240110208

Document status and date:

Published: 01/01/1988

\section{Document Version:}

Publisher's PDF, also known as Version of Record (includes final page, issue and volume numbers)

\section{Please check the document version of this publication:}

- A submitted manuscript is the version of the article upon submission and before peer-review. There can be important differences between the submitted version and the official published version of record. People interested in the research are advised to contact the author for the final version of the publication, or visit the $\mathrm{DOI}$ to the publisher's website.

- The final author version and the galley proof are versions of the publication after peer review.

- The final published version features the final layout of the paper including the volume, issue and page numbers.

Link to publication

\footnotetext{
General rights

- You may freely distribute the URL identifying the publication in the public portal. follow below link for the End User Agreement:

www.tue.nl/taverne

Take down policy

If you believe that this document breaches copyright please contact us at:

openaccess@tue.nl

providing details and we will investigate your claim.
}

Copyright and moral rights for the publications made accessible in the public portal are retained by the authors and/or other copyright owners and it is a condition of accessing publications that users recognise and abide by the legal requirements associated with these rights.

- Users may download and print one copy of any publication from the public portal for the purpose of private study or research.

- You may not further distribute the material or use it for any profit-making activity or commercial gain

If the publication is distributed under the terms of Article $25 \mathrm{fa}$ of the Dutch Copyright Act, indicated by the "Taverne" license above, please 


\section{On-Line Combination of Liquid Chromatography and Capillary Gas Chromatography. Preconcentration and Analysis of Organic Compounds in Aqueous Samples}

Th. Noy ${ }^{1)}$, E. Weiss, T. Herps, H. Van Cruchten ${ }^{2)}$, and J. Rijks*

Eindhoven University of Technology, Dept. of Chemical Engineering, Lab. Instrumental Analysis, P. O. Box 513, 5600 MB Eindhoven, The Netherlands

Key Words:

Capillary GC

Coupled LC-GC

Large injection volumes

Trace analysis

Aqueous samples

\section{Summary}

This paper describes the design of a new, versatile, and low-cost on-line LC-GC interface that allows the fast and reliable introduction of large sample volumes onto a capillary GC column. The sample introduction procedure consists successively of: evaporation of the entire sample (LC fraction), selective removal of the solvent and simultaneously cold-trapping of the solutes, splitless transfer of the solutes to the GC column, on-column focusing, GC separation and detection. Quantitative and qualitative aspects of various experimental parameters are evaluated and optimum conditions are reported. The applicability of the method is demonstrated on a synthetic aqueous sample of chlorinated pesticides.

\section{Introduction}

In chromatography there is an increasing interest in the analysis of very low concentrations of organic compounds in complex samples. As these concentrations are often too low to be determined directly, sample preconcentration techniques have to be applied. Among them the combination of liquid chromatography and capillary gas chromatography is very promising.

As a preseparation technique, liquid chromatography adds selectivity to the high efficiency of capillary gas chromatography, thus improving the overall separation potential. Moreover, when LC is employed for sample preconcentration, the LC-GC combination provides a very sensitive analytical technique.

GC analyses of off-line LC preseparated fractions is a universally adopted analytical procedure [1-3]. Generally only a small part of the total volume of the LC fraction is used for GC analysis. Direct introduction of the entire LC fraction, however, drastically improves the detectability of trace

\footnotetext{
1) Present address: KIWA NV, P.O. Box 1072, 3430 BB Nieuwegein, The Netherlands

2) Present address: Enka B. V., P.O. Box 60, 6800 AB Arnhem, The Netherlands
}

\author{
Presented at the \\ Eighth International Symposium \\ on Capillary Chromatography
}

compounds, while contamination, losses, and the overall analysis time are considerably reduced. In addition, it is easily automated.

For the on-line LC-GC combination two possible approaches occur: the adjustment of $L C$ to $G C$ requirements, resulting in a micro-LC version $[4,6]$, or the adaption of the $\mathrm{GC}$ instrument to the introduction of very large volumes of liquid sample, typically $20-1000 \mu l$. Injection techniques appropriate for the introduction of such large sample volumes include PTV injections [7,9], injections on a packed pre-column $[10,11]$, a specially designed injection device incorporating a $500 \mu$ reservoir [12], and several on-column injection techniques using very long retention gaps [13] or applying concurrent solvent evaporation [14,17]. The latter has been used successfully in the on-line combination of LC and GC [14-17]. The on-column injections, however, require long sampling times and the applications are limited to non-polar solvents.

The design, the optimization and the evaluation of a new LC-GC interface, that allows the fast introduction of large sample volumes onto a capillary GC-column, are presented in this paper.

\section{Experimental}

\subsection{System Design}

A schematic design of the LC-GC interface is given in Figure 1.

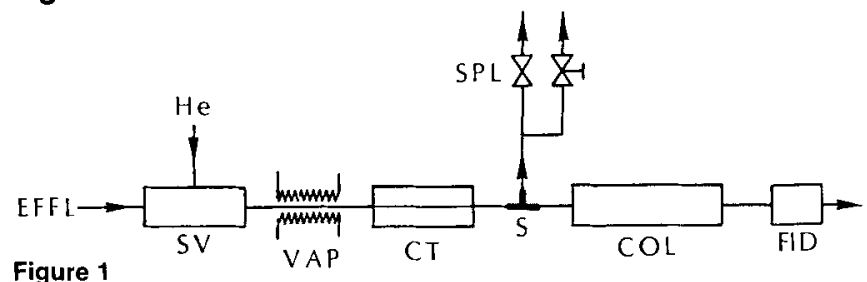

Figure 1

Schematic design of the LC-GC interface design. EFFL $=$ LC effluent, SV = sampling valve, VAP $=$ vaporizer, $\mathbf{S}=$ all-glass low dead volume T-splitting device, $\mathrm{CT}=$ cold-trap, $\mathrm{COL}=\mathrm{GC}$-column, $\mathrm{SPL}=$ splitter valves, FID $=$ Flame ionization detector. 
The system consists of a sampling valve connecting the LC and GC instruments, a vaporizer, a short fused silica capillary cold-trap and a specially designed low dead volume $\mathrm{t}$-splitting device.

Two different sampling valves were used during this study. They are given in detail in Figure 2.

$\mathrm{a}$

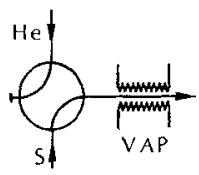

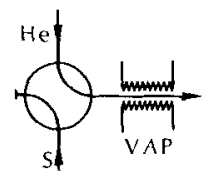

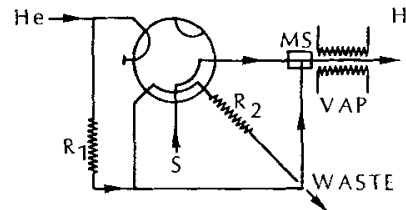

1

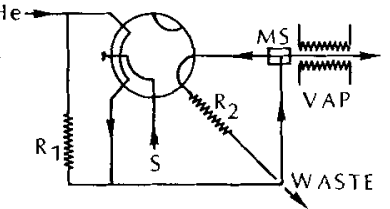

II

Figure 2

Sampling valves. a. 4-port switching valve $b$. 6-port switching valve. $I$. Sample introduction. II. GC-analysis and back flush. $\mathbf{S}=$ sample; $\mathbf{R}_{1}, \mathbf{R}_{2}$ $=$ restrictions; $M S=$ mixing + splitting device; VAP $=$ vaporizer.

The 4-port switching valve was used in most of the experiments. The cold-trap capillary is passed through the vaporizer and connected directly to the 4-port valve. The 6-port valve system was designed to enable back flushing of the switching valve in order to avoid memory effects. A memory- and dead volume free mixing and splitting device was constructed by sliding a $50 \mu \mathrm{m}$ i.d. capillary into a $320 \mu \mathrm{m}$ i.d. column, as shown schematically in Figure 3.

a

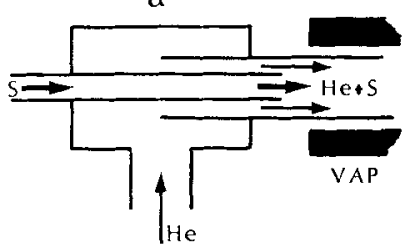

Figure 3

Mixing and splitting device of the 6-port valve system (Swagelock ${ }^{\mathrm{R}}$ $1 / 16$ " union-T). a. Sample introduction. b. GC analysis and back flush. $S$ = sample; VAP $=$ vaporizer.

In addition, the mixing of the sample with helium provides a more gentle evaporation. During sampling, the carrier gas flow through the cold-trap is limited by a restriction $\left(R_{1}\right.$ in Fig. 2 b). In this way an early breakthrough of volatile compounds can be avoided.

The vaporizer and the low dead volume T-splitting device are schematically presented in Figure 4.

In the vaporizer the cold-trap capillary is passed through a closely fitting brass insert, placed in the heated GC-injection port. The column connections to the $T$-splitter can be made either by Swagelock ${ }^{R}$ reducing unions $\left(1 / 8^{\prime \prime} \times 1 / 16^{\prime \prime}\right)$ or by polyimide glue.
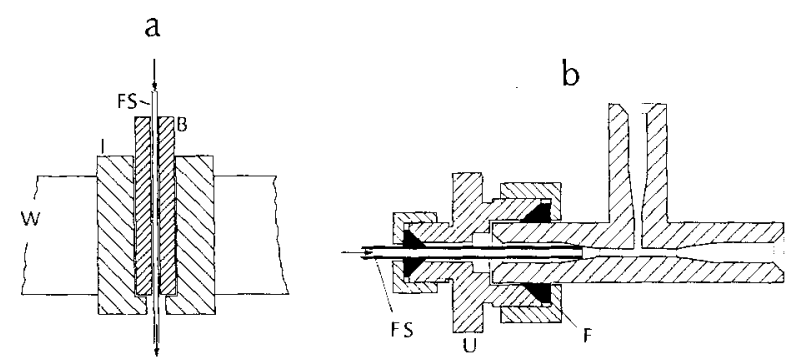

Figure 4

Schematics of the vaporizer (a) and the all-glass low dead volume $T$. splitter (b). FS = fused silica capillary: $I=G C$ injection port; $W=G C$ oven wall; $B=$ Brass insert, $L=100 \mathrm{~mm}, 0 . d .=6 \mathrm{~mm} ; U=$ reducing union $(1 / 8 " \times 1 / 16$ "); $F=$ Vespel ferrule.

\subsection{Sample Transfer}

Because of the need of an easy exchange of stock solutions in studying the introduction of large sample volumes, the samples were delivered by a pressurized glass container instead of using an LC pump. The sample container was connected to either one of the switching valves by . means of a flexible fused silica capillary $(0.6 \mathrm{~m} \times 50 \mu \mathrm{m}$ i. d.). The amount of liquid introduced in this way was determined gravimetrically.

After evaporation of the entire sample in the vaporizer, the solutes are retained in the cold-trap while the solvent vapor is passed and largely removed via the split vent. The coldtrap is a short fused silica capillary column installed in the GC oven compartment, connecting the valve system to the splitting device. In order to avoid recondensation of the solvent, the trap temperature (i. e., the initial oven temperature) is maintained slightly above the solvent boiling point.

After introduction of the desired sample volume, the valve is switched. Simultaneously the splitter valve is closed and the GC oven temperature program is started. On increasing the oven temperature the trapped solutes are transferred to the GC column via the T-splitting device. Back diffusion of solvent vapor to the column is prevented by a parallel split line incorporating a needle valve, thus establishing a small constant gas flow.

Unless stated otherwise, the analyses were performed according to the standard experimental conditions of Table 1.

\section{Table 1}

Standard experimental conditions.

\begin{tabular}{lll}
\hline Sample & volume & $40-100 \mu l$ \\
& flow rate & $40 \mu 1 / \mathrm{min}$ \\
Cold-trap & type & uncoated fused silica \\
& dimensions & $2 \mathrm{~m} \times 0.25 \mathrm{~mm}$ i.d. \\
& temperature & $70^{\circ} \mathrm{C}$ \\
Vaporizer & temperature & $250^{\circ} \mathrm{C}$ \\
\hline
\end{tabular}




\subsection{Gas Chromatography}

The equipment was built on top of a HP 5880 gas chromatograph (Hewlett Packard, Avondale, PA, USA) provided with a FID and an ECD detector. Throughout this study two different separation columns were used: a. a home-made fused silica SE-54 column ( $L=15 \mathrm{~m}$, i. d. $=0.31 \mathrm{~mm}, d_{f}=$ approximately $0.3 \mu \mathrm{m}$ ), temperature program: $70^{\circ} \mathrm{C}$ up to $280^{\circ} \mathrm{C}$ at $8^{\circ} / \mathrm{min}$, and b. a $11.5 \mathrm{~m} \times 0.2 \mathrm{~mm}$ i. d. crosslinked OV-1 fused silica column $\left(d_{f}=0.11 \mu \mathrm{m}\right.$ ) (Hewlett Packard, Avondale, PA, USA), programmed from $70^{\circ} \mathrm{C}$ up to $280^{\circ} \mathrm{C}$ at $20 \% \mathrm{~min}$.

Synthetic stock solutions containing $n$-hydrocarbons in redistilled $n$-hexane were prepared in concentrations of $100 \mathrm{ng} / \mathrm{ml}(100 \mathrm{ppb} \mathrm{m} / \mathrm{v})$.

\section{Results and Discussion}

\subsection{Accuracy and Reproducibility}

In order to examine the extent to which quantitative sample transfer ("recovery") could be achieved, the LC-GC sample introduction was compared to on-column injectors of $1 \mu \mathrm{l}$ of a more concentrated stock solution. The cold-trap capillary was connected to a HP on-column injector for this purpose. During on-column sampling the splitter valve was closed.

The recoveries as well as the relative standard deviation (RSD) of reproduced sample introduction are given in Table 2.

\section{Table 2}

Recovery and reproducibility $(n=5)$ of sample transier by the LC-GC interface for the 4-port (a) as well as the 6-port valve system (b).

\begin{tabular}{lccc} 
& & \multicolumn{2}{l}{ RSD (\%) } \\
\cline { 3 - 4 } Hydrocarbon & Recovery (\%) & (a) & (b) \\
\hline$n-C 15$ & 14 & 5.6 & - \\
$n-C 16$ & 22 & 8.6 & - \\
$n-C 20$ & 102 & 1.7 & 2.7 \\
$n-C 22$ & 99 & 2.0 & 2.8 \\
$n-C 24$ & 99 & 1.1 & 5.2 \\
$n-C 26$ & 98 & 0.6 & 3.4 \\
\hline
\end{tabular}

Solutes with a volatility less than $n-\mathrm{C} 20$ are retained quantitatively by the uncoated cold-trap, whereas more volatile compounds are partly vented via the splitter. The reproducibility is excellent for non-volatiles and still surprisingly good for the incompletely recovered solutes. In agreement with this, the detector response for non-volatile compounds correlates very well with the sample volume introduced by the 4-port valve (cf. Figure 5). The corresponding correlation coefficients are 0.999 for $n-\mathrm{C} 20$ and only 0.96 for $n-\mathrm{C} 16$.
Similar results were obtained for the 6-port valve system: for hydrocarbons with 20 up to 30 carbon atoms, the correlation coefficients exceeded the value of 0.998 .
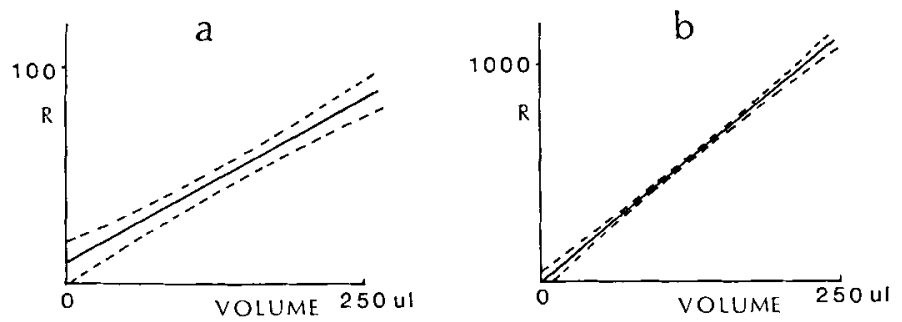

Figure 5

Correlation between sample volume and detector response (R) for $n-C_{16}$ (a) and $n-\mathrm{C} 20$ (b), including the $95 \%$ reliability intervals.

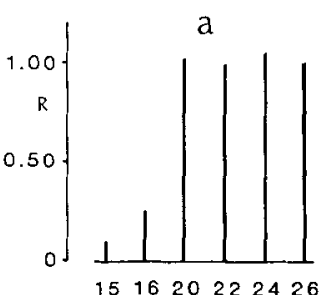

Figure 6 b

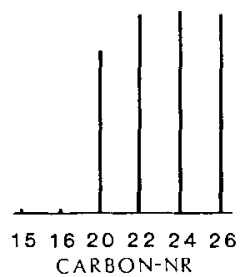

$\mathrm{C}$

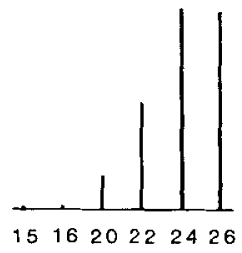

Recoveries $(R)$ of several $n$-hydrocarbons at different cold-trap temperatures. $a=70^{\circ} \mathrm{C} ; b=80^{\circ} \mathrm{C} ; c=100^{\circ} \mathrm{C}$.

\subsection{Influence of the Cold-Trap Temperature}

As shown already by Table 2, a quantitative sample transfer is obtained for compounds which are less volatile than $n$ $\mathrm{C} 20$ at a cold-trap temperature of $70^{\circ} \mathrm{C}$. Increasing this temperature results in a faster solute transport along the cold-trap capillary and consequently more of it is lost. The effect of the cold-trap temperature on the recovery of some hydrocarbons is shown in Figure. 6. Even a small temperature elevation results in a considerable increase of the losses for the more volatile compounds.

As demonstrated by the example of Figure 7, a decrease of the cold-trap temperature below the boiling point of the solvent gives rise to serious losses and/or bad peak shapes. This is due to recondensation of the solvent, which results in passage of the solutes through the cold-trap capillary. a

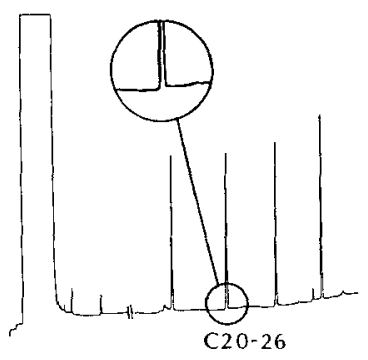

Figure 7 b

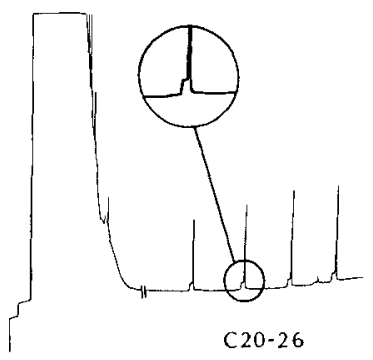

The effect of recondensation of the solvent. a: cold-trap at $70^{\circ} \mathrm{C}$; b: coldtrap at $65^{\circ} \mathrm{C}$; even numbered hydrocarbons $n-\mathrm{C} 20-n-\mathrm{C} 26$. 


\subsection{Influence of the Cold-Trap Stationary Phase Film Thickness}

On increasing the stationary phase film thickness, the retention time of the solutes in the cold-trap is increased as well. Figure 8 shows considerable improvements in the recoveries of volatile solutes when the uncoated cold-trap is replaced by a cold-trap with a stationary phase coating $\left(2 \mathrm{~m} \times 0.25 \mathrm{~mm}\right.$ i. $\mathrm{d}_{\mathrm{d}}, \mathrm{d}_{\mathrm{f}}=0.14 \mu \mathrm{m}$, immobilized OV-1, homemade).
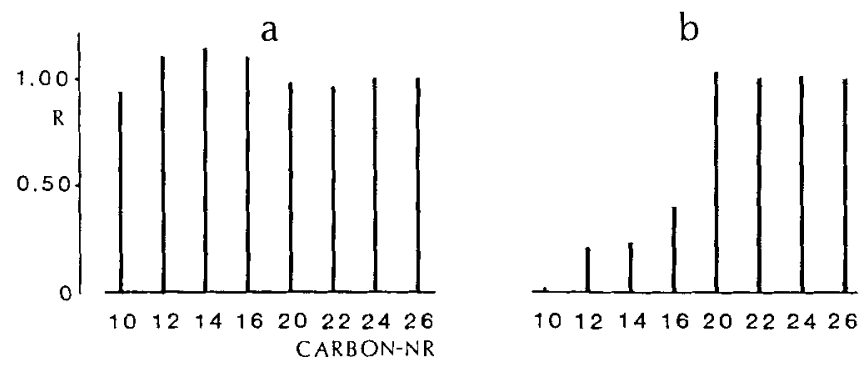

Figure 8

Comparison of the recoveries $(R)$ on a coated and an uncoated capillary cold-trap for $n-\mathrm{C} 10-n$-C26 (4-port valve system). a: $2 \mathrm{~m} \times 0.25 \mathrm{~mm} \mathrm{i.d.,}$ immobilized oV-1, $d_{1}=0.14 \mu \mathrm{m}, b: 2 \mathrm{~m} \times 0.25 \mathrm{~mm}$ i. d., uncoated and non-deactivated.

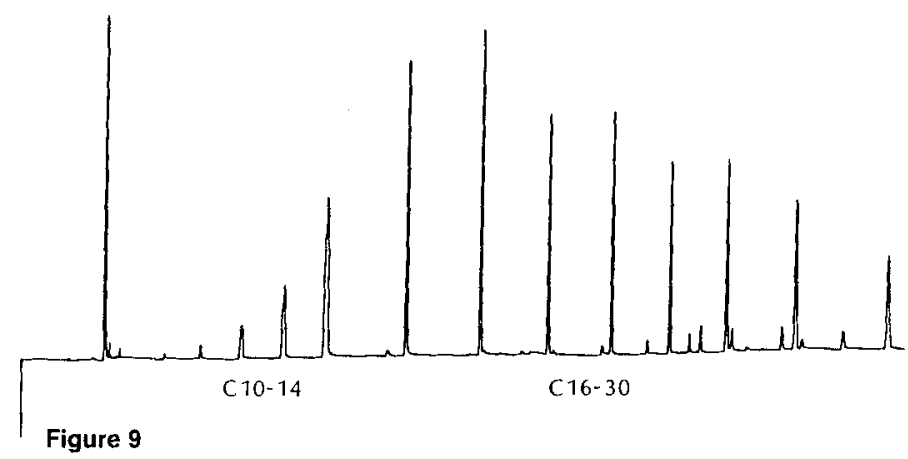

Chromatogram of $100 \mu$ of a hydrocarbon solution ( $n-\mathrm{C}_{10}-n-\mathrm{C} 14$, even numbered $n-\mathrm{C}_{16}-n-\mathrm{C} 30,100 \mathrm{ppb}$ in $n$-hexane) using a coated cold-trap $\left(5 \mathrm{~m} \times 0.31 \mathrm{~mm}\right.$ i. d., CP SIL 5 CB, $d_{f}=0.11 \mu \mathrm{m}$ ) in combination with the 6-port valve system.
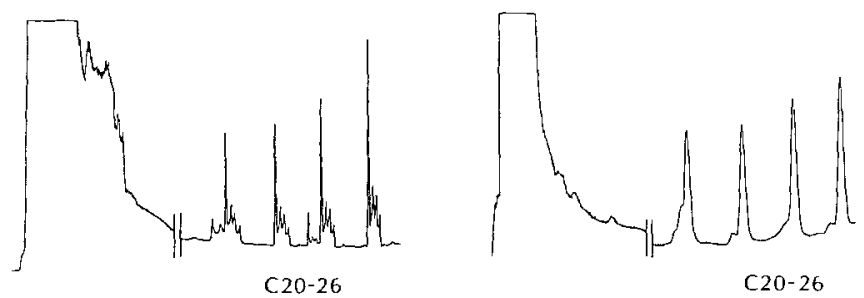

Figure 10

Chromatograms after damaging of the cold-trap stationary phase film.

The applicability of coated cold-traps is determined by the stability of the immobilized stationary phase, the resistance of the stationary phase coating to solvent damage, as well as by the refocusing capacity of the GC column. This phase gradient refocusing, i. e., the reduction of the band width of the deposited solutes in the cold-trap by the stationary phase film inside the GC column, is directly proportional to the retention ratio and thus the ratio of the film thicknesses of the separation column and the cold-trap capillary.

As shown by Figure 9, using a coated cold-trap, compounds more volatile than $n-\mathrm{C} 20$ are also quantitatively trapped ( $n-\mathrm{C} 14-n-\mathrm{C} 18)$. Components with a volatility higher than $n-\mathrm{C} 14$ are partly lost during trapping. Because in this experiment the film thickness of the cold-trap and the GC column are of the same order, no phase gradient refocusing can be expected. Obviously $n-C 14$ is deposited along a considerable length of the cold-trap capillary, whereas the less volatile hydrocarbons are deposited as reasonably narrow bands in the cold-trap.

The application of coated cold-traps requires a very careful selection of the immobilized stationary phase. In contact with the liquid solvent the stationary phase swells and becomes very vulnerable. We assume that in the environment of boiling solvent sheets of the stationary phase film are torn off the inner column wall and are deposited further downstream in the cold-trap capillary, in the T-splitter, or even in the GC-column. Apart from the reduced trapping capacity, this irregular stationary phase distribution causes peak splitting or extreme peak broadening (Figure 10). Using a coated cold-trap like the one of Fig. 7a $(2 \mathrm{~m} \times$ $0.25 \mathrm{~mm}$ i. d., immobilized OV-1, $d_{f}=0.14 \mu \mathrm{m}$ ), connected to the 4-port valve system, clogging of the $\mathrm{GC}$ column was observed. With the combination of the 6-port valve system and the cold-trap, presented in Figure 8, none of these problems have occurred during a period of about four months.

\subsection{Influence of the Vaporizer Temperature}

The LC-GC interface performance is hardly affected by the vaporizer temperature. Only when the vaporizer temperature is far below the solute elution temperature, compounds may remain trapped in the vaporizer as they are not submitted to the GC oven temperature program (e.g. at a vaporizer temperature of $150^{\circ} \mathrm{C}$ less than $25 \%$ of $n-\mathrm{C} 30$ hydrocarbon, eluting at $280^{\circ} \mathrm{C}$, was recovered).

\subsection{Influence of Sample Flow Rate}

When the sample flow rate is too high, incomplete evaporation occurs and the solutes are transported with the liquid solvent along the cold-trap. Similar to the observations on recondensation at too low cold-trap temperatures, bad peak shapes result (Figure 11).

For the quoted experimental conditions a sample flow rate of $150 \mu \mathrm{l} / \mathrm{min}$ is the upper limit.

\subsection{Influence of Solvent Type}

Injection techniques employing the solvent effect for solute focusing [13-17] are limited to non-polar solvents due to wettability problems of the coated column inner wall by polar solvents. Consequently, LC-GC interfaces based on 
a
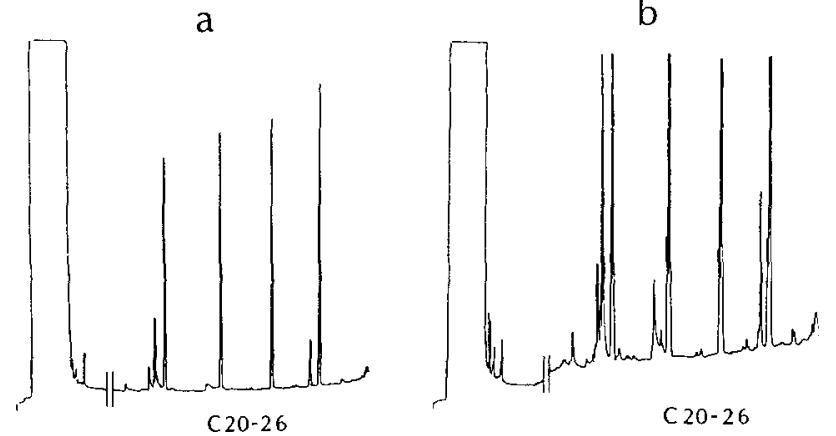

C 20-26

Figure 11

Eflect of the sample flow rate on the peak shape in combination with the 4-port valve system. a: $100 \mu \mathrm{l} / \mathrm{min}$. b: $300 \mu \mathrm{l} / \mathrm{min}$; hydrocarbons evennumbered $\mathrm{nC} 20-\mathrm{nC} 26$.

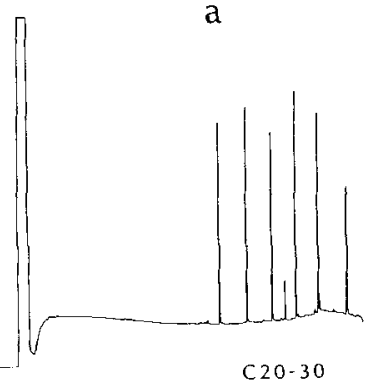

$\mathrm{b}$

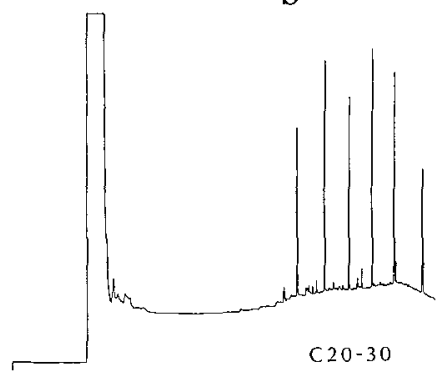

Figure 12

Chromatograms of $100 \mathrm{ppb}$ solutions of hydrocarbons (even numbered $n$-C20- $n$-C30) in $n$-hexane (a) and methanol respectively (b); sample volume $=100 \mu \mathrm{l}$, sample flow rate $=100 \mu \mathrm{l} / \mathrm{min}$ in combination with the 6-port valve system.

on-column sampling can only be applied for straight phase LC effluents. Nowadays, however, reversed phase HPLC has become the predominant $L C$ technique.

In our equipment the entire sample with a volume from 20 up to $1000 \mu$ is evaporated, followed by cold-trapping and on-column phase gradient refocusing. This process is not influenced by the solvent polarity, as shown in Figure 12, where comparative chromatograms of hydrocarbon solutions in methanol respectively and $n$-hexane are given, which are introduced under equal conditions. Neither the peak areas nor the peak shapes are affected by the solvent type.

\subsection{Introduction of Extremely Large Sample Volumes}

Figure 13 shows a chromatogram of $1000 \mu$ of a $n$-hexane solution containing $10 \mathrm{ppb}$ of even-numbered $n$-hydrocarbons $(\mathrm{C} 20-\mathrm{C} 30)$. On introduction at a flow rate of approx. $100 \mu \mathrm{l} / \mathrm{min}$, a large solvent peak appears.

After adjustment of the zero signal and attenuation, contaminant peaks appear as well. They correspond to concentrations of $1-50 \mathrm{ppb} w / \mathrm{v}$. Obviously the purity of the redistilled hexane was not sufficient. This example illustrates

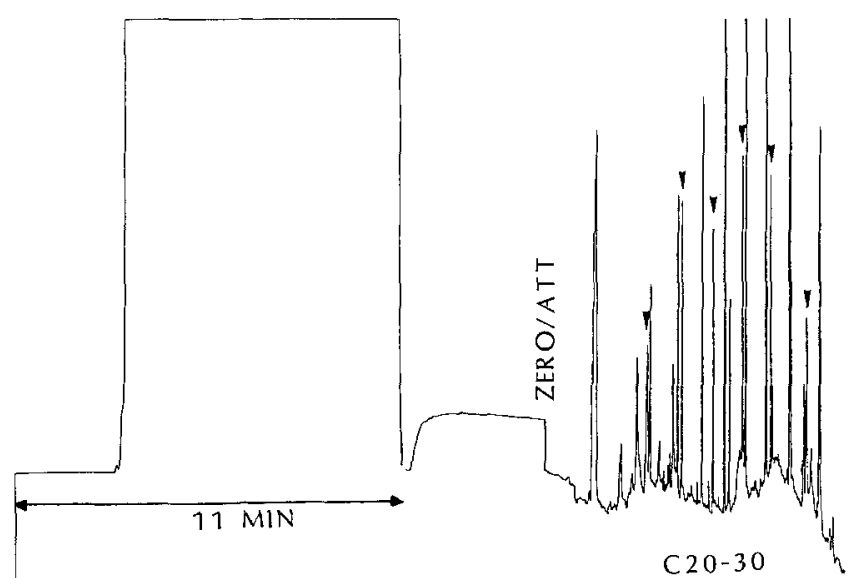

Figure 13

Chromatogram of $1000 \mu$ of a diluted $n$-hydrocarbon sample $n$-C20-C30, $10 \mathrm{ppb} \mathrm{w} / \mathrm{v} /$ compound), the hydrocarbons are indicated by arrows.

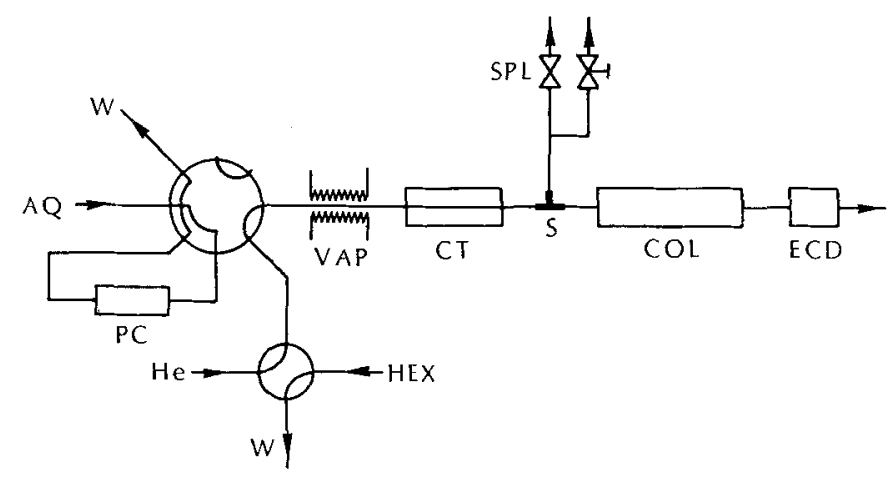

Figure 14

Equipment for the on-line combination of LC-preconcentration and HRGC separation. $A Q=$ aqueous sample, $P C=$ pre-column, $W=$ waste, HEX $=n$-hexane, $C T=$ cold-trap, VAP $=$ vaporizer, $S=T$-splitting device, $\mathrm{SPL}=$ splitter valves, $\mathrm{COL}=\mathrm{GC}$ column, $\mathrm{ECD}=$ electron capture detector.

the limitations of all kinds of applications of ultra-trace analysis: the availability of highly pure solvents and gases and extremely clean glassware, tubing, syringes, etc.

\subsection{The On-Line Combination of LC and GC}

The purpose of this work was the accomplishment of the on-line combination of LC-preseparation or LC-preconcentration and capillary GC separation. Although additional research is required for further improvement of this system, a preliminary example of the analysis of a diluted aqueous sample of chlorinated pesticides is presented. The equipment for pre-concentration, extraction, and sample transfer is shown in Figure 14.

A six-port valve incorporating a $\mathrm{C}-18$ modified silica precolumn $\left(10 \mathrm{~mm} \times 2 \mathrm{~mm}\right.$ i. d., $\left.d_{\mathrm{p}}=20 \mu \mathrm{m}\right)$ is supplementary to the evaluated equipment. $A 12 \mathrm{ml}$ sample volume of the aqueous solution containing approx. $100 \mathrm{ppt} /$ compound was passed over the pre-column. After drying of the pre- 


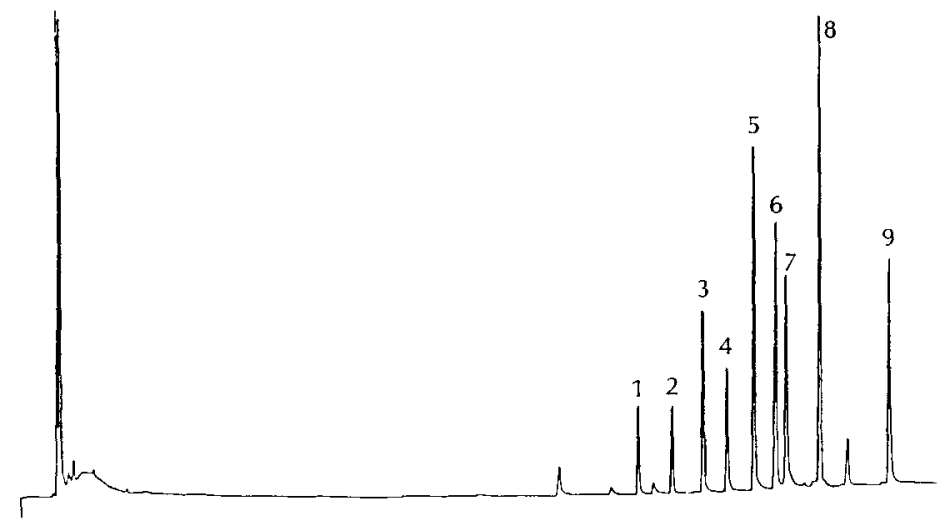

Figure 15

Chromatogram of chlorinated pesticides concentrated from $12 \mathrm{ml}$ aqueous sample containing $100 \mathrm{ppt} /$ compound, and extracted with $70 \mu \mathrm{l} n$-hexane. Cold-trap: $\mathrm{L}=2 \mathrm{~m}$, i. d. $=0.25 \mathrm{~mm}$, uncoated. $1=$ $\gamma \cdot \mathbf{H C H} ; 2=$ heptachlor; $3=$ aldrin; $\mathbf{4}=$ heptachlorepoxide; $5=$ $o, p$-DDE; $6=p, p$-DDE; $7=$ endrin; $8=p, p$-DDD; $9=p, p$-DDT. column by the combination of He-flushing and applying vacuum, the pre-column was extracted by a small amount of $n$-hexane (ca. $70 \mu \mathrm{l})$. The resulting chromatogram is shown in Figure 15.

\section{Conclusions}

The presented on-line LC-GC interface enables the reliable introduction of large liquid sample volumes $(20-1000 \mu l)$ onto a capillary column in a relatively short time. The 6-port valve system appears an attractive device for sample transfer, allowing back flushing in order to avoid memory effects and gentle evaporation of the solvent.

The performance of the LC-GC interface is mainly determined by the efficiency of the capillary cold-trap. Because the trapping temperature should be as low as possible, but always above the boiling point of the solvent, low boiling solvents are most advantageous. The presence of a stationary phase film inside the cold-trap benefits the recovery of more volatile components, but reduces the effect of phase gradient refocusing by the GC column. Compounds less volatile than $n$-C14 can be trapped quantitatively on a short thin film capillary cold-trap.

The performance of the LC-GC interface is hardly affected by the vaporizer temperature nor by the sample flow rate unless it is too high in relation to the vaporizer temperature and length.

Polar and non-polar solvents, as well as extremely large sample volumes can be introduced so that the system can be applied for ultra trace analysis of organic compounds in a wide variety of samples.

\section{Acknowledgment}

For the fruitful discussions E. Noroozian, F. A. Maris, and U. A.Th. Brinkman of the Free University of Amsterdam are kindly acknowledged.

\section{References}

[1] F. DeSanzo, P. Uden, and S. Siggia, Anal.Chem. 52 (1980) 906-909.

[2] R. L. Miller, L. S. Ettre, and N. G. Johansen, J. Chromatogr. 264 (1983) 19-32.

[3] P. de Voogt, J. C. Klamer, and H. Govers, J. Chromatogr. 363 (1986) 407-411.

[4] M.W. F. Nielen, R. C.A. Koordes, R. W. Frei, and U. A. Th. Brinkman, J. Chromatogr. 330 (1985) 113-119.

[5] H. J. Cortes, C. D. Pfeiffer, and B. E. Richter, HRC \& CC 8 (1985) 469-474.

[6] H. J. Cortes, B. E. Richter, C. D. Pfeiffer, and D. E. Jensen, J. Chromatogr. 349 (1985) 55-61.

[7] W. Vogt, K. Jacob, and H. W. Obwexer, J. Chromatogr. 174 (1979) 437-439.

[8] W. Vogt, K. Jacob, A. B. Ohnesorge, and H. W. Obwexer, J. Chromatogr. 186 (1979) 197-205.

[9] F. Poy, Chromatographia 16 (1982) 345-348.

[10] T. H. Mague and P. L. Sherman, J. Chromatogr. Sci. 20 (1982) 225-227.

[11] P. Kirschmer and M. Oehme, HRC \& CC 7 (1984) 306-311.

[12] F. Etzweiler, HRC \& CC 8 (1985) 85.

[13] K. Grob, G. Karrer, and M. L. Riekkola, J. Chromatogr. 334 (1985) 129-155.

[14] F. Munari, A. Trisciani, G. Mapelli, S. Trestianu, K. Grob, and J. Colin, HRC \& CC 8 (1985) 601-606.

[15] K. Grob and B. Schilling, HRC \& CC 8 (1985) 726-733.

[16] K. Grob, C. Walder, and B. Schilling, HRC \& CC 9 (1986) 95-101.

[17 E. Noroozian, F. A. Maris, M. W. F. Nielen, R. W. Frei, G. J. de Jong, and U. A. Th. Brinkman, HRC \& CC 10 (1987) 17. 